University of Nebraska - Lincoln

DigitalCommons@University of Nebraska - Lincoln

Publications from USDA-ARS / UNL Faculty

U.S. Department of Agriculture: Agricultural

Research Service, Lincoln, Nebraska

November 2003

\title{
Phenological responses of wheat and barley to water and temperature: improving simulation models
}

G. S. McMaster

USDA-ARS, Great Plains Systems Research, greg.mcmaster@ars.usda.gov

Wally Wilhelm

University of Nebraska-Lincoln, wally.wilhelm@ars.usda.gov

Follow this and additional works at: https://digitalcommons.unl.edu/usdaarsfacpub

Part of the Agricultural Science Commons

McMaster, G. S. and Wilhelm, Wally, "Phenological responses of wheat and barley to water and temperature: improving simulation models" (2003). Publications from USDA-ARS / UNL Faculty. 75. https://digitalcommons.unl.edu/usdaarsfacpub/75

This Article is brought to you for free and open access by the U.S. Department of Agriculture: Agricultural Research Service, Lincoln, Nebraska at DigitalCommons@University of Nebraska - Lincoln. It has been accepted for inclusion in Publications from USDA-ARS / UNL Faculty by an authorized administrator of DigitalCommons@University of Nebraska - Lincoln. 


\title{
Phenological responses of wheat and barley to water and temperature: improving simulation models
}

\author{
G. S. MCMASTER ${ }^{1 *}$ AND W. W. WILHELM ${ }^{2}$ \\ ${ }^{1}$ USDA-ARS, Great Plains Systems Research, 301 S. Howes St., Room 353, Fort Collins, \\ CO 80521, USA \\ ${ }^{2}$ USDA-ARS, Soil and Water Conservation Research, 120 Keim Hall, University of Nebraska, Lincoln, \\ NE 68583, USA
}

(Revised MS received 15 July 2003)

\begin{abstract}
SUMMARY
Understanding and predicting small-grain cereal development is becoming increasingly important in enhancing management practices. Recent efforts to improve phenology submodels in crop simulations have focused on incorporating developmental responses to water stress and interpreting and understanding thermal time. The objectives of the present study were to evaluate data from three experiments to (a) determine the qualitative and quantitative response of wheat (Triticum aestivum L.) and barley (Hordeum vulgare L.) to water stress and (b) ascertain where in space to measure temperature, to provide information required to improve phenological submodels. The first experiment tested the phenological responses of 12 winter wheat cultivars to water stress for two seasons at two sites. The second experiment tested the timing of water stress on spring barley phenological responses for 2 years. In a third experiment, soil near the shoot apex of field-grown spring wheat was heated to $3{ }^{\circ} \mathrm{C}$ above ambient soil temperature for three planting dates in each of 2 years, to test whether it is better to use soil or air temperature in calculating thermal time. The general response of wheat and barley to water stress was to reach growth stages earlier (i.e. to hasten development). The most significant response was for the grain filling period. Water stress had little effect on jointing and flag leaf complete/booting growth stages. Thermal time to jointing was highly variable across locations. However, thermal time to subsequent growth stages was very consistent both within and across locations. The winter wheat cultivars tested followed this general response across site-years, but inconsistencies were found, suggesting a complicated genotype by environment $(\mathrm{G} \times \mathrm{E})$ interaction that makes improving phenology submodels for all cultivars difficult. The $\mathrm{G} \times \mathrm{E}$ interaction was most prominent for anthesis (A) and maturity (M) growth stages. Results of heating the soil at the shoot apex depth were completely unexpected: heating the soil did not speed spring wheat phenological development. These results, and others cited, suggest caution in allocating effort and resources to measuring or estimating soil temperature rather than relying on readily available air temperature as a means of universally improving phenology submodels. These results help quantify the response of wheat to water stress and thermal time for improving crop simulation models and management.
\end{abstract}

\section{INTRODUCTION}

Understanding and predicting crop development is fundamental to many aspects of agronomy including optimizing crop management practices such as herbicide, fertilizer and irrigation applications. Phenology submodels are also critical components of crop

* To whom all correspondence should be addressed. Email: Greg.McMaster@ars.usda.gov simulation models, and crop models are increasingly being utilized as part of decision aids to assess specific strategic and tactical crop cultural practice alternatives.

From the beginning of crop modelling, the primary importance of temperature has been recognized, and it is therefore used to drive phenology submodels. Many of the earliest crop simulation models (e.g. CERES-Wheat and WINTER WHEAT, Willis 1985; EPIC, Williams et al. 1989) had relatively low levels 
of phenological detail and used temperature (almost exclusively) to predict a few growth stages (McMaster 1993). In the late 1980s and early 1990s a new generation of small-grain cereal crop simulation models was developed that were developmentally driven rather than energy or carbon driven. Although these models (e.g. ARCWHEAT, Weir et al. 1984; SHOOTGRO, McMaster et al. 1991, $1992 a, b$; Wilhelm et al. 1993; MODWht, Rickman et al. 1996; Sirius, Jamieson et al. 1998) contained significantly greater phenological and developmental detail gained from insights derived from several decades of research, they still were primarily driven by temperature. Since their inception, efforts to improve these developmentally driven models have focused on two areas: improving the temperature response and incorporating the role of secondary factors that influence wheat phenology, particularly water stress.

One area of effort to improve the temperature response has focused on several aspects of thermal time: how to calculate thermal time (McMaster \& Wilhelm 1997), moving towards a non-linear representation of thermal time (Cao \& Moss 1989; Yan \& Hunt 1999; Streck et al. 2003), and where to measure temperature. Some research and theories suggest that using soil temperature at the depth of the shoot apex will refine predictions (Hay \& Wilson 1982; Jamieson et al. 1995; Vinocur \& Ritchie 2001), but others suggest the improvements will be negligible (McMaster \& Wilhelm 1998; McMaster et al. 2003). It remains an open question whether using soil temperature rather than air temperature will significantly improve wheat phenology submodels.

While temperature is the primary environmental factor controlling development of wheat, other factors such as light, water, salinity, nutrients and $\mathrm{CO}_{2}$ play secondary, but sometimes important, roles (Bauer et al. 1984; Baker et al. 1986; Maas \& Grieve 1990; Longnecker et al. 1993; Wilhelm \& McMaster 1995; McMaster 1997; McMaster et al. 1999). Often these factors interact, and in the case of water, salinity and light, it is difficult to separate the interaction from the main effect of temperature. Some phenology submodels do not consider secondary factors, while most of the others do not address them adequately. For the majority of wheat production regions where water is a limiting factor, inadequately accounting for phenological responses to water stress limits application of the models or submodels as management decision tools.

To improve the response of wheat phenology submodels to water stress and temperature, greater understanding and more descriptive data are needed to address several questions. How does water stress affect each developmental growth stage, both qualitatively and quantitatively? Do all cultivars have the same general response to water stress, or does the genotype by environment $(\mathrm{G} \times \mathrm{E})$ interaction have to be described if significant progress is to be made? How reliable are the general maturity classifications of cultivars as a basis of adjusting thermal time for growth stages in simulations? Does the time and expense of either measuring or predicting soil temperature provide significant improvement in predicting wheat phenology over using air temperature to calculate thermal time? Is the thermal time concept sufficient for modelling small grain development? The objective of the present paper is to provide new data to combine with existing knowledge to answer these questions and, in turn, suggest approaches to improve wheat phenology submodels.

\section{METHODS}

Three field experiments described below were conducted to study the phenological responses of wheat and barley to water and temperature stresses. In all experiments, Method 1 of McMaster \& Wilhelm (1997) was used when calculating air and soil growing degree-days (GDD), where the average daily temperature is compared with the base temperature and positive values are accumulated. A base temperature of $0{ }^{\circ} \mathrm{C}$ was used (Baker et al. 1986; McMaster \& Smika 1988). Dates are expressed as day of year (DOY), commencing 1 January $=1$.

The SAS statistical package (SAS 1991) was used for data analysis. Analysis of variance was computed using the general linear model (PROC GLM). Mean separation procedures consisted of the Fisher's Protected Least Significant Difference test (LSD, $\alpha=0 \cdot 05)$.

\section{Experiment I}

This experiment examined winter wheat phenological responses to water stress. The experiment was a 2-year study conducted at the Colorado State University Agricultural Research Development and Education Center (denoted ARDEC; $40^{\circ} 39^{\prime} \mathrm{N}, 105^{\circ} 00^{\prime} \mathrm{W}$, $1534 \mathrm{~m}$ a.s.l., soil type a fine, smectitic, mesic, Aridic Argiustoll) and Akron, Colorado, USDA-ARS Central Great Plains Research Station (denoted Akron; $40^{\circ} 09^{\prime} \mathrm{N}, 103^{\circ} 09^{\prime} \mathrm{W}, 1384 \mathrm{~m}$ a.s.l., soil type a fine, smectitic, mesic, Pachic Argiustoll), both initiated in autumn 1999. Twelve winter wheat varieties, presumed to differ in heat and drought tolerance, were grown under dryland and irrigated treatments (except Halt and Yumar were not grown 1999-2000 in Akron). Most varieties are commonly used in this region, but some are adapted to other environments (e.g. Norstar, Siouxland). The experimental design was a split-plot with dryland/irrigation the main-plot and cultivar the split-plot factors. Replications differed by locations and years: two replications for 1999-2000 at both locations (Akron, subplot error D.F. $=18$; ARDEC subplot error D.F. $=22$ ), and three 
(Akron, subplot error D.F. $=44$ ) and four (ARDEC, subplot error D.F. $=66$ ) replications for 2000-01.

Plot size was $1.85 \times 4.6 \mathrm{~m} \mathrm{(1999-2000)}$ and $1.85 \times$ $6.1 \mathrm{~m} \mathrm{(2000-01)}$ at ARDEC and $4.6 \times 12.2 \mathrm{~m}$ at Akron with $31 \mathrm{~cm}$ (ARDEC) and $19 \mathrm{~cm}$ (Akron) row spacing. Before planting, the soil was tilled using a mouldboard plough to a depth of approximately $20 \mathrm{~cm}$ followed by roller harrow. Furrows were established between raised beds consisting of two rows at ARDEC. Seeding rate was 1852500 seeds/ha. Approximately $67 \mathrm{~kg} \mathrm{~N} / \mathrm{ha}$ at ARDEC and $56 \mathrm{~kg}$ $\mathrm{N} / \mathrm{ha}$ and $17 \mathrm{~kg} \mathrm{P} / \mathrm{ha}$ at Akron was broadcast prior to planting. Application rates were based on soil analyses and appropriate recommendation algorithms.

Irrigation was applied weekly beginning mid-April at Akron by solid-set overhead impact sprinklers to balance water use predicted from Penman-Monteith reference evapotranspiration with an applied crop coefficient appropriate for wheat. Total irrigation water applied was $294 \mathrm{~mm}$ in 1999-2000 and $165 \mathrm{~mm}$ in 2000-01. Irrigation treatments at ARDEC consisted of furrow irrigation with water applied to alternate rows. The 1999-2000 irrigation treatment began on 25 March (near the double ridge growth stage) and the 2000-01 irrigation treatment began on 11 May (just after jointing). Generally irrigation is not applied prior to jointing because soil water is adequate to meet plant demand in the winter and spring period. During the first season, water was applied about every 2 weeks. During the second season, water was applied weekly.

Plant emergence (ARDEC location only) was measured three times per week, weather permitting, for $1 \mathrm{~m}$ of row located in the centre of each plot. The main stems of 10 successive plants within each of these $1-\mathrm{m}$ row segments were marked and phenological growth stages of each main stem observed at least three times per week, again weather permitting. Growth stages were defined as in McMaster (1997) and based on the Feekes growth stage scale (Large 1954) where jointing ( $\mathrm{J}$; approximately Zadoks 31 ; Zadoks et al. 1974) was defined as the time when the first node of the main stem appeared above the soil surface; flag leaf complete (FLC; Zadoks 39) was defined as the appearance of the collar of the flag leaf and was considered the beginning of booting (when the spike appears as a swelling within the leaf sheaths); heading ( $\mathrm{H}$; Zadoks 50$)$ was defined as when the spike just appeared, normally by extending through the collar of the flag leaf; anthesis (A) was defined as the beginning of anther appearance (Zadoks 61); and physiological maturity (M; approximately Zadoks 91) was defined as the complete absence of green colour in all spike components (e.g. glumes, paleas, lemmas, rachises and rachillae). Cumulative leaf number (Haun 1973) was recorded periodically for the main stem, using marking techniques described in McMaster et al. (1994).

\section{Experiment II}

This field experiment, a 2-year study beginning in spring 1997, was conducted northeast of Fort Collins, Colorado, USA, at the Colorado State University Horticulture Farm $\left(40^{\circ} 36^{\prime} \mathrm{N}, 104^{\circ} 59^{\prime} \mathrm{W}\right)$ on a Nunn clay loam soil (fine, smectitic, mesic Aridic, Argiustoll). The experimental design was a complete randomized block with four blocks and two main treatments: a pre-planting tillage operation and a no-tillage treatment. Tillage treatment plot size was $12 \cdot 2 \times 27 \cdot 4 \mathrm{~m}$. Within each tillage treatment block, five irrigation treatments were applied (subplot size was $2 \times 2 \mathrm{~m}$ ): dryland (no irrigation), fully irrigated (from emergence to physiological maturity), irrigated from emergence to jointing, irrigated from jointing to anthesis, and irrigated from anthesis to maturity. Irrigation water, $2.5 \mathrm{~cm}$, was applied at approximately weekly intervals with sprinklers. Spring barley (cv. Steptoe) was planted on 10 March 1997 and 17 March 1998 at a rate of $78.4 \mathrm{~kg}$ seed/ha (1000 seed weight was $41 \cdot 89 \mathrm{~g}$ ). Row spacing was $30 \mathrm{~cm}$, and $39 \cdot 2 \mathrm{~kg} \mathrm{~N} / \mathrm{ha}$ and $22 \cdot 4 \mathrm{~kg} \mathrm{P} /$ ha was broadcast following planting.

As with Expt I, 10 successive plants within a row in the centre of the plot were marked for seedling emergence and subsequent phenological measurements of the main stem. Phenological measurements of jointing, flag leaf complete, heading, anthesis start, and physiological maturity were made at least three times weekly, weather permitting.

\section{Experiment III}

This 2-year field experiment began in the spring 1998, and was also conducted at the Colorado State University Horticulture Farm on a site near Expt II. Spring wheat (cv. Nordic), which is reported to be photoperiod sensitive, was grown in a randomized complete block design with four blocks. Treatments were planting date and soil temperature. Planting dates were 24 March, 13 April and 5 May 1998 and 16 March, 13 April and 14 May 1999. The first planting date in a year is denoted as PD1, the second as PD2 and the third as PD3. The two levels of soil temperature at $2-3 \mathrm{~cm}$ depth were ambient soil temperature (denoted as $+0{ }^{\circ} \mathrm{C}$ ) and $+3{ }^{\circ} \mathrm{C}$ above ambient (denoted $+3{ }^{\circ} \mathrm{C}$ ).

Plot size was $1 \times 1 \mathrm{~m}$, with 5 rows of wheat per plot. Before the first planting date of each year, the soil was rototilled to a depth of approximately $15 \mathrm{~cm}$. For each row, a trench was dug to a depth of $6 \mathrm{~cm}$, then layered with $1 \mathrm{~cm}$ of soil, a $1.25 \mathrm{~cm}$ wide strip of heat tape (in the $+3 \mathrm{C}$ treatment) or duct tape folded to the thickness and width of the heat tape (in the $+0 \mathrm{C}$ treatment) placed along the row, and $3 \mathrm{~cm}$ of soil layered on top of the tape. Next seeds were placed into the trench. Thermocouples were placed into the trench, in the middle row only, at seed depth. Two $\mathrm{cm}$ 
Table 1. Pooled means of 12 winter wheat cultivars in the ARDEC and Akron locations for day of year (DOY) to various growth stages (Expt I). Emergence data were not collected at the Akron location

\begin{tabular}{|c|c|c|c|c|c|c|c|c|c|}
\hline \multirow[b]{2}{*}{ Growth stage } & \multicolumn{3}{|c|}{ 1999-2000 } & \multicolumn{3}{|c|}{$2000-2001$} & \multicolumn{3}{|c|}{ Mean (both years) } \\
\hline & $\begin{array}{l}\text { Irrigated } \\
\text { (DOY) }\end{array}$ & $\begin{array}{c}\text { Dryland } \\
\text { (DOY) }\end{array}$ & $\begin{array}{l}\text { Difference } \\
\text { (days) }\end{array}$ & $\begin{array}{l}\text { Irrigated } \\
\text { (DOY) }\end{array}$ & $\begin{array}{c}\text { Dryland } \\
\text { (DOY) }\end{array}$ & $\begin{array}{l}\text { Difference } \\
\text { (days) }\end{array}$ & $\begin{array}{l}\text { Irrigated } \\
\text { (DOY) }\end{array}$ & $\begin{array}{l}\text { Dryland } \\
\text { (DOY) }\end{array}$ & $\begin{array}{l}\text { Difference } \\
\quad \text { (days) }\end{array}$ \\
\hline \multicolumn{10}{|l|}{ ARDEC, Colorado } \\
\hline Emergence & $289 \cdot 6$ & $289 \cdot 5$ & $0 \cdot 1$ & $299 \cdot 3$ & $299 \cdot 4$ & $-0 \cdot 1$ & $294 \cdot 3$ & $294 \cdot 5$ & $-0 \cdot 2$ \\
\hline Jointing & $118 \cdot 6 \dagger$ & $117 \cdot 7$ & $0 \cdot 9$ & $130 \cdot 0 \%$ & $130 \cdot 4$ & $-0 \cdot 4$ & $124 \cdot 3$ & $124 \cdot 1$ & $0 \cdot 2$ \\
\hline Flag leaf complete & $127 \cdot 3$ & $124 \cdot 6$ & $2 \cdot 7 * *$ & $144 \cdot 3$ & $144 \cdot 1$ & $0 \cdot 2$ & $135 \cdot 8$ & $134 \cdot 1$ & $1 \cdot 4$ \\
\hline Heading & $138 \cdot 4$ & $134 \cdot 1$ & $4 \cdot 3^{* *}$ & 154 & $151 \cdot 4$ & $2 \cdot 6^{* *}$ & $146 \cdot 2$ & $142 \cdot 8$ & $3 \cdot 4^{* *}$ \\
\hline Anthesis & $151 \cdot 1$ & 144 & $7 \cdot 1 * *$ & 161 & $160 \cdot 1$ & $0 \cdot 9$ & $156 \cdot 1$ & $152 \cdot 1$ & $4 \cdot 0$ \\
\hline Maturity & $188 \cdot 2$ & $176 \cdot 1$ & $12 \cdot 1 * *$ & $198 \cdot 7$ & $186 \cdot 4$ & $12 \cdot 3 * *$ & $193 \cdot 5$ & $181 \cdot 3$ & $12 \cdot 2 * *$ \\
\hline \multicolumn{10}{|l|}{ Akron, Colorado } \\
\hline Jointing & $120 \cdot 2 \S$ & $116 \cdot 6$ & $3 \cdot 6^{* *}$ & $129 \cdot 1 \S$ & $128 \cdot 7$ & $0 \cdot 4$ & $124 \cdot 7$ & $122 \cdot 7$ & $2 \cdot 0$ \\
\hline Flag leaf complete & $130 \cdot 1$ & $129 \cdot 1$ & $1^{*}$ & $139 \cdot 3$ & $138 \cdot 5$ & $0 \cdot 8^{* *}$ & $134 \cdot 7$ & $133 \cdot 8$ & $0 \cdot 9 * *$ \\
\hline Heading & $143 \cdot 1$ & $140 \cdot 7$ & $2 \cdot 4^{* *}$ & $152 \cdot 6$ & $151 \cdot 8$ & $0 \cdot 8$ & $147 \cdot 9$ & $146 \cdot 3$ & $1 \cdot 6^{*}$ \\
\hline Anthesis & 151 & $148 \cdot 5$ & $2 \cdot 5^{* *}$ & 157 & $156 \cdot 1$ & $0 \cdot 9 *$ & 154 & $152 \cdot 3$ & $1 \cdot 7 * *$ \\
\hline Maturity & $183 \cdot 6$ & $174 \cdot 1$ & $9 \cdot 5^{* *}$ & $187 \cdot 3$ & $183 \cdot 8$ & $3 \cdot 5^{* *}$ & $185 \cdot 5$ & 179 & $6 \cdot 5^{* *}$ \\
\hline
\end{tabular}

* Significant at 0.05 level, ** Significant at 0.01 level.

$\uparrow$ Irrigation began on DOY 83.

* Irrigation began on DOY 131.

$\S$ Irrigation began near mid-April (about DOY 105).

of soil were placed over the seeds and thermocouples resulting in a $2 \mathrm{~cm}$ seed depth. Seed spacing was $2 \mathrm{~cm}$, giving a seeding density of 250 seeds $/ \mathrm{m}^{2}$. Irrigation, to ensure uniform germination, immediately followed planting, and fertilizer was broadcast at a rate of $39 \mathrm{~kg} \mathrm{~N} / \mathrm{ha}$ and $22 \mathrm{~kg} \mathrm{P} / \mathrm{ha}$. Plot management consisted of hand weeding and twice monthly (first year) and weekly (second year) irrigations of 19 litres water per plot beginning within 2 weeks after planting.

Soil temperatures at $2 \mathrm{~cm}$ depths (approximate crown depth) were measured with copper-constantan thermocouples placed in the soil as described in the previous paragraph. Three thermocouples were connected in parallel to give a mean output. Thermocouple output was recorded each minute with a data logger; daily maximum, minimum and average temperatures were calculated and stored. For each block, when the difference in temperature within a planting date between the $+0 \mathrm{C}$ and $+3 \mathrm{C}$ treatments became less than $3{ }^{\circ} \mathrm{C}$, power was supplied to the heat tape until the $3{ }^{\circ} \mathrm{C}$ temperature differential was reestablished. Temperature differences between soil temperature treatments were maintained within $0 \cdot 1{ }^{\circ} \mathrm{C}$ of the target $3{ }^{\circ} \mathrm{C}$. Daily weather data were collected from a Class A weather station at the site.

Seedling emergence for $50 \mathrm{~cm}$ of the middle row was observed daily, unless weather conditions did not permit access to the plots or if snow covered the plots. Plant measurements were made repeatedly on 10 plants in the middle row of the plot. Cumulative leaf number (Haun 1973) was recorded at least weekly for the main stem. Phenological growth stages (as defined above for Expt I) were observed at least three times a week, weather permitting.

\section{RESULTS}

Precipitation for the growing season (1 September through 31 July) for Expt I at ARDEC was $109 \mathrm{~mm}$ in 1999-2000 and $221 \mathrm{~mm}$ in 2000-01 (long-term mean is $295 \mathrm{~mm}$ ), and at Akron was $186 \mathrm{~mm}$ in 1999 2000 and $346 \mathrm{~mm}$ in 2000-01 (long-term mean is $367 \mathrm{~mm}$ ). For both Expts II and III, the growing season precipitation (from 1 March through 31 August) was $242 \mathrm{~mm}$ in 1997, $194 \mathrm{~mm}$ in 1998 and $296 \mathrm{~mm}$ in 1999 (long-term mean is $237 \mathrm{~mm}$ ).

\section{Experiment I}

\section{General response of winter wheat to water stress}

Pooling cultivars within a water stress treatment (Table 1) shows that all growth stages other than emergence and jointing (except 1999-2000 at ARDEC) were reached earlier under water stressed (dryland) conditions. The fact that water stress did not affect jointing date was not too surprising for two reasons. First, in some site-years (e.g. 2000-01 season at ARDEC) the irrigation treatment had not begun. Second, generally water stress is not severe following normal winter and early spring precipitation and there is a relatively low evaporative demand due to short days and cool temperatures characteristic for 
that time of year. The cumulative effect of water stress resulted in greater differences in day of year (DOY) between treatments for later growth stages, particularly maturity. For instance, no significant difference for jointing (except Akron 1999-2000) was observed. Differences in time of flag leaf complete/booting (FLC) were significant for 3 of the 4 site-years, although differences between irrigated and dryland treatments (mean of both years) was only 1.4 days at ARDEC and 0.9 days (NS) at Akron. By maturity, the mean (over years) difference in timing between water stress treatments was 6.5 days (Akron) and 12.2 days (ARDEC), both highly significant.

Thermal time, as represented by growing degreedays (GDD), is a more useful way to quantify the water stress response, particularly since the number of days varies with time of year (i.e. mean daily temperature) and between years. In general, similar responses were found whether thermal time (Table 2) or DOY (Table 1) was used. Thus, all phenological stages (except jointing and FLC in 2000-01) were achieved in fewer days or less thermal time under stress conditions. There was a slight increase in the difference between treatments in number of GDD with successive growth stages (not significant for J, FLC and $\mathrm{H}$ when combining years at a site), but as for DOY, the primary difference was for maturity. Water stress treatment differences were slightly greater at ARDEC than Akron.

Within a treatment and location, the thermal time accumulated after 1 January was similar between years for each growth stage (Table 2). However, Akron reached the jointing growth stage over 200 GDD later than ARDEC (but DOY for jointing was similar for both sites), regardless of treatment; this difference was generally maintained for successive growth stages. ARDEC GDD values from 1 January to jointing are within the normal range reported (McMaster \& Smika 1988; McMaster et al. 2002; and unpublished data), and the authors do not know why Akron values were high. This suggests that the thermal time required to reach a growth stage within a location is relatively stable, but can differ between locations. Similar results were observed when comparing locations in the Central Great Plains (McMaster \& Smika 1988), although conditions differed considerably among locations confounding this inference.

Treatment had little and inconsistent effect on the difference in thermal time for the intervals between growth stages prior to grain filling (J-FLC, FLC-H and $\mathrm{H}-\mathrm{A}$ ) and highly significant effect on the grainfilling interval (A-M; Table 3). Despite more than 200 GDD accumulating from 1 January to jointing at Akron than at ARDEC, once jointing was achieved, the thermal time between successive stages was similar between locations, regardless of treatment. The only exception was the $\mathrm{H}-\mathrm{A}$ interval at 


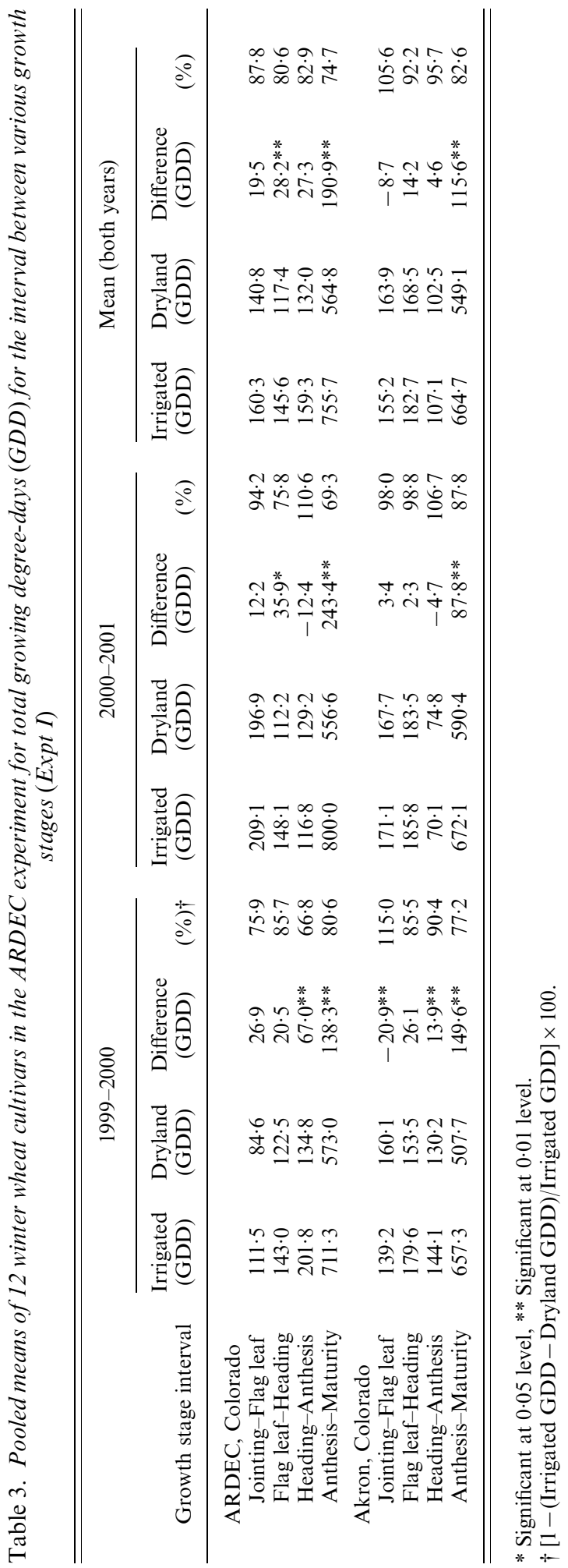

Akron where the interval was about $50 \%$ greater for the 1999-2000 season compared with the 2000-01 season.

\section{Do all cultivars respond similarly to water stress?}

Comparing how individual cultivars respond to water stress against the pooled cultivar mean identifies whether modifications are needed to improve simulating specific cultivar responses. In almost every case, cultivars achieved each growth stage at different times within a water treatment.

For the jointing growth stage, all cultivars did not respond the same as the mean of the pooled cultivars (Fig. 1). For three of the four site-years (not ARDEC 1999-2000), cultivars within a treatment reached jointing at significantly different dates (Fig. 1). No specific cultivar(s) caused this difference across siteyears. Most cultivars reached jointing slightly sooner in the dryland treatment. Omitting the second year at ARDEC (because irrigation had not started), five cultivars (Norstar, Jagger, Heyne, Halt and Alliance) consistently reached jointing slightly earlier (although usually not significantly) in the dryland treatment, and Siouxland consistently reached jointing slightly later (significant only in Akron 1999-2000; Tables 4 and 5).

Cultivar response to water stress was more consistent for the flag leaf complete/booting growth stage than jointing. A highly significant difference among cultivars, within a treatment, reaching FLC was observed for all site-years (Fig. 2). This was primarily because Norstar was much later than all other cultivars. However, cultivar ranking within a treatment did not change between irrigated and dryland treatments (Tables 4 and 5).

For heading, all cultivars responded similarly to the pooled mean response where heading was reached earlier under water stress (Fig. 3). Again, highly significant differences among cultivars within a treatment reaching heading were observed for all siteyears. A few varieties in specific site-years showed relatively greater response to water stress, changing the cultivar ranking (e.g. Jagger in 1999-2000 at ARDEC, Yumar and Akron in 2000-01 at ARDEC, and Prowers 99, Alliance, and Heyne in 1999-2000 at Akron; Tables 4 and 5). However, although cultivar rankings occasionally changed, treatment differences for that cultivar were not always significant (e.g. Jagger and Prowers 99 listed above).

The pattern observed for flag leaf complete and heading was also found for anthesis and maturity, where anthesis and maturity were reached earlier under water stress by all cultivars (Figs 4 and 5). With the exception of anthesis in the irrigated treatment in 1999-2000 at ARDEC, cultivars within a treatment differed significantly at each site-year for both anthesis and maturity, but cultivars did not always significantly differ between treatments at specific siteyears (more so for anthesis than maturity). However, 

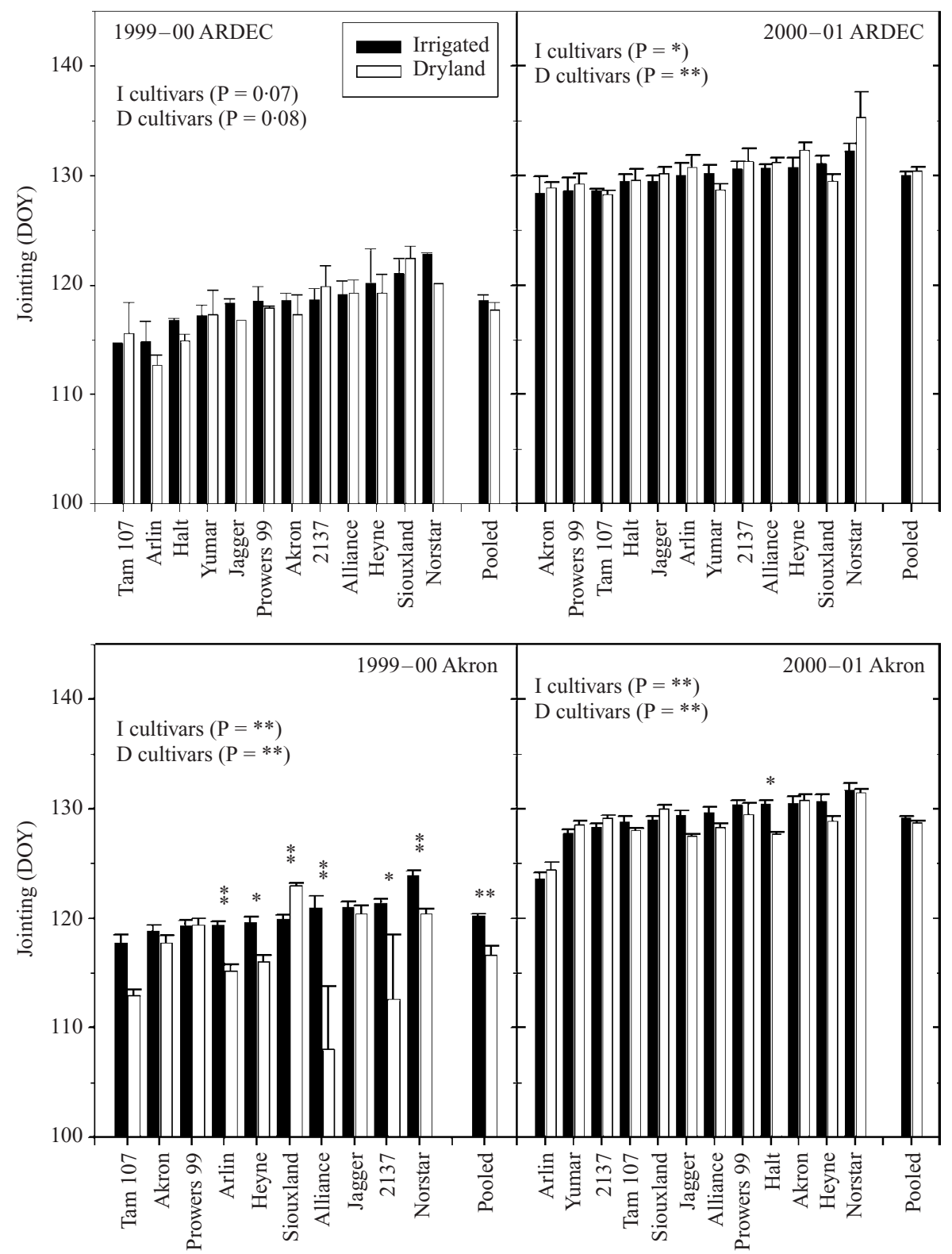

Fig. 1. Day of year jointing was reached for the winter wheat water stress experiment at ARDEC and Akron locations (Expt I). Statistical results for comparing cultivar differences within a treatment ( $\mathrm{I}=$ irrigated, $\mathrm{D}=$ dryland) are presented below the site-year label. Comparison of irrigated to dryland results for each cultivar (or the pooled means) are noted above the bars. A single asterisk denotes significant at 0.05 level, and double asterisk significant at 0.01 level.

cultivars varied in their degree of response between years and locations (Tables 4 and 5). Notable examples for anthesis during 1999-2000 at ARDEC, the rank of TAM 107 rose from 11th (late) in the irrigated treatment to 2nd (early) in the dryland treatment, in 2000-01 at ARDEC Yumar rose from 7th to 1st, but
Jagger changed in the opposite direction, 3rd in irrigated to 11 th in dryland. Cultivar rankings differed by less than four positions, except for Prowers 99 at anthesis, which rose from 9th (irrigated) to 5th (dryland) in 1999-2000 at Akron. Similar contrasting responses can be observed for maturity with other 
Table 4. Winter wheat cultivar rankings (earliest to latest) for ARDEC location (Expt I)

\begin{tabular}{|c|c|c|c|c|c|c|c|c|c|c|c|c|c|c|c|}
\hline \multirow[b]{2}{*}{ Variety } & \multicolumn{3}{|c|}{ Jointing } & \multicolumn{3}{|c|}{ Flag leaf complete } & \multicolumn{3}{|c|}{ Heading } & \multicolumn{3}{|c|}{ Anthesis } & \multicolumn{3}{|c|}{ Maturity } \\
\hline & Irrig & Dry & Diff & Irrig & Dry & Diff & Irrig & Dry & Diff & Irrig & Dry & Diff & Irrig & Dry & Diff \\
\hline \multicolumn{16}{|l|}{ 1999-2000 } \\
\hline 2137 & 8 & 10 & -2 & 7 & 9 & -2 & 8 & 5 & $3 *$ & 5 & 10 & $-5^{*}$ & 7 & 4 & $3 *$ \\
\hline Akron & 7 & 6 & 1 & 6 & 6 & 0 & 4 & 8 & $-4 *$ & 7 & 6 & 1 & 4 & 7 & $-3^{*}$ \\
\hline Alliance & 9 & 8 & 1 & 9 & 4 & $5^{*}$ & 6 & 6 & 0 & 4 & 3 & 1 & 6 & 6 & 0 \\
\hline Arlin & 1 & 1 & 0 & 1 & 1 & 0 & 1 & 1 & 0 & 1 & 1 & 0 & 2 & 1 & 1 \\
\hline Halt & 3 & 2 & 1 & 3 & 2 & 1 & 2 & 2 & 0 & 2 & 5 & $-3^{*}$ & 3 & 3 & 0 \\
\hline Heyne & 10 & 9 & 1 & 11 & 10 & 1 & 9 & 9 & 0 & 6 & 9 & $-3^{*}$ & 5 & 8 & $-3^{*}$ \\
\hline Jagger & 5 & 4 & 1 & 4 & 5 & -1 & 5 & 4 & 1 & 3 & 4 & -1 & 1 & 2 & -1 \\
\hline Norstar & 12 & 11 & 1 & 12 & 12 & 0 & 12 & 12 & 0 & 12 & 12 & 0 & 12 & 12 & 0 \\
\hline Prowers 99 & 6 & 7 & -1 & 5 & 7 & -2 & 10 & 10 & 0 & 10 & 7 & $3^{*}$ & 11 & 9 & 2 \\
\hline Siouxland & 11 & 12 & -1 & 10 & 11 & -1 & 11 & 11 & 0 & 8 & 11 & $-3^{*}$ & 10 & 11 & -1 \\
\hline TAM 107 & 2 & 3 & -1 & 2 & 3 & -1 & 3 & 3 & 0 & 11 & 2 & $9^{*}$ & 8 & 5 & 3* \\
\hline Yumar & 4 & 5 & -1 & 8 & 8 & 0 & 7 & 7 & 0 & 9 & 8 & 1 & 9 & 10 & -1 \\
\hline \multicolumn{16}{|l|}{$2000-2001$} \\
\hline 2137 & 9 & 11 & -2 & 7 & 9 & -2 & 8 & 8 & 0 & 10 & 10 & 0 & 11 & 8 & $3 *$ \\
\hline Akron & 4 & 4 & 0 & 6 & 7 & -1 & 7 & 7 & 0 & 6 & 7 & -1 & 4 & 7 & $-3^{*}$ \\
\hline Alliance & 10 & 10 & 0 & 10 & 11 & -1 & 10 & 10 & 0 & 8 & 6 & 2 & 3 & 5 & -2 \\
\hline Arlin & 7 & 9 & -2 & 5 & 5 & 0 & 1 & 6 & $-5^{*}$ & 5 & 5 & 0 & 9 & 11 & -2 \\
\hline Halt & 6 & 7 & -1 & 1 & 6 & $-5^{*}$ & 5 & 5 & 0 & 4 & 4 & 0 & 2 & 1 & 1 \\
\hline Heyne & 1 & 1 & 0 & 2 & 1 & 1 & 3 & 2 & 1 & 1 & 2 & -1 & 5 & 3 & 2 \\
\hline Jagger & 5 & 8 & $-3^{*}$ & 4 & 4 & 0 & 2 & 1 & 1 & 3 & 11 & $-8^{*}$ & 1 & 2 & -1 \\
\hline Norstar & 12 & 12 & 0 & 12 & 12 & 0 & 12 & 12 & 0 & 12 & 12 & 0 & 12 & 12 & 0 \\
\hline Prowers 99 & 3 & 5 & -2 & 8 & 10 & -2 & 6 & 11 & $-5^{*}$ & 9 & 8 & 1 & 8 & 10 & -2 \\
\hline Siouxland & 11 & 6 & $5^{*}$ & 11 & 8 & $3^{*}$ & 11 & 9 & 2 & 11 & 9 & 2 & 7 & 9 & -2 \\
\hline TAM 107 & 2 & 2 & 0 & 3 & 2 & 1 & 4 & 3 & 1 & 2 & 3 & -1 & 6 & 4 & 2 \\
\hline Yumar & 8 & 3 & $5^{*}$ & 9 & 3 & $6^{*}$ & 3 & 4 & -1 & 7 & 1 & $6^{*}$ & 10 & 6 & $4^{*}$ \\
\hline
\end{tabular}

* Differences $>2$ rankings.

cultivars. As in the case with the heading growth stage, we do not know why cultivars responded with so many inconsistencies given that the general response of all cultivars to water stress was to reach anthesis and maturity earlier.

\section{Experiment II}

In contrast to Expt I, which examined the cumulative effect of water stress on phenology for different winter wheat cultivars, Expt II examined the timing of water stress on phenological development in a spring barley variety (Fig. 6). In comparing the two treatments most similar to Expt I (the dryland, DRY, and irrigated from emergence through maturity, ALL), the same response to water stress was observed: except for jointing water stress caused a growth stage to occur earlier, and the effect was greater for later growth stages. Although at specific growth stages irrigated and dryland treatments were not always significantly different, the irrigated treatment means were greater than or equal to the dryland means (except for anthesis in 1998 when irrigation from jointing to heading resulted in earlier flowering than any other treatment).
The other irrigation treatments did not seem to fit a predictable pattern, but differences were relatively small. The $\mathrm{E}$ to $\mathrm{J}$ irrigation treatment had no effect on delaying phenology except for FLC and $\mathrm{H}$ in the second year. Irrigating from A to M did slightly delay maturity. This matches results from Experiment $\mathrm{I}$ in that the $\mathrm{A}$ to $\mathrm{M}$ interval (via changing $\mathrm{M}$ ) was the most responsive to water stress.

\section{Experiment III}

\section{Is it better to use soil temperature rather than air temperature?}

Temperature and water stress are often correlated and it is difficult to independently separate the effects of each. However, this experiment, where the soil at the point of the shoot apex was heated $3{ }^{\circ} \mathrm{C}$ above the ambient soil temperature, specifically addressed this issue by altering temperature in relatively unstressed conditions for water, so only the direct temperature effect can be discerned. The expectation was that plants in the $+3 \mathrm{C}$ treatment should reach growth stages (at least while the shoot apex is in the crown) earlier than the ambient $(+0 \mathrm{C})$ treatment, yet this 
Table 5. Winter wheat cultivar rankings (earliest to latest) for Akron location (Expt I)

\begin{tabular}{|c|c|c|c|c|c|c|c|c|c|c|c|c|c|c|c|}
\hline \multirow[b]{2}{*}{ Variety } & \multicolumn{3}{|c|}{ Jointing } & \multicolumn{3}{|c|}{ Flag leaf complete } & \multicolumn{3}{|c|}{ Heading } & \multicolumn{3}{|c|}{ Anthesis } & \multicolumn{3}{|c|}{ Maturity } \\
\hline & Irrig & Dry & Diff & Irrig & Dry & Diff & Irrig & Dry & Diff & Irrig & Dry & Diff & Irrig & Dry & Diff \\
\hline \multicolumn{16}{|l|}{ 1999-2000 } \\
\hline 2137 & 9 & 2 & $7 *$ & 9 & 6 & $3 *$ & 7 & 8 & -1 & 8 & 8 & 0 & 8 & 4 & $4^{*}$ \\
\hline Akron & 2 & 6 & $-4 *$ & 5 & 8 & $-3^{*}$ & 4 & 7 & $-3^{*}$ & 3 & 6 & $-3^{*}$ & 5 & 5 & 0 \\
\hline Alliance & 7 & 1 & $6^{*}$ & 4 & 1 & $3 *$ & 5 & 3 & 2 & 4 & 3 & 1 & 3 & 3 & 0 \\
\hline Arlin & 4 & 4 & 0 & 1 & 4 & $-3^{*}$ & 2 & 2 & 0 & 6 & 9 & $-3^{*}$ & 9 & 1 & $8^{*}$ \\
\hline Halt $\dagger$ & & & & & & & & & & & & & & & \\
\hline Heyne & 5 & 5 & 0 & 6 & 5 & 1 & 6 & 4 & 2 & 5 & 2 & $3^{*}$ & 4 & 6 & -2 \\
\hline Jagger & 8 & 8 & 0 & 3 & 7 & $-4 *$ & 3 & 5 & -2 & 2 & 4 & -2 & 2 & 8 & $-6^{*}$ \\
\hline Norstar & 10 & 9 & 1 & 10 & 10 & 0 & 10 & 10 & 0 & 10 & 10 & 0 & 10 & 10 & 0 \\
\hline Prowers 99 & 3 & 7 & $-4 *$ & 7 & 3 & $4 *$ & 9 & 6 & $3 *$ & 9 & 5 & $4 *$ & 6 & 9 & $-3^{*}$ \\
\hline Siouxland & 6 & 10 & $-4 *$ & 8 & 9 & -1 & 8 & 9 & -1 & 7 & 7 & 0 & 7 & 7 & 0 \\
\hline TAM 107 & 1 & 3 & -2 & 2 & 2 & 0 & 1 & 1 & 0 & 1 & 1 & 0 & 1 & 2 & -1 \\
\hline Yumar† & & & & & & & & & & & & & & & \\
\hline \multicolumn{16}{|l|}{$2000-2001$} \\
\hline 2137 & 3 & 8 & $-5^{*}$ & 4 & 7 & $-3^{*}$ & 8 & 8 & 0 & 9 & 8 & 1 & 3 & 3 & 0 \\
\hline Akron & 10 & 11 & -1 & 9 & 8 & 1 & 7 & 7 & 0 & 8 & 6 & 2 & 5 & 4 & 1 \\
\hline Alliance & 7 & 5 & 2 & 7 & 4 & $3 *$ & 5 & 6 & -1 & 5 & 5 & 0 & 2 & 2 & 0 \\
\hline Arlin & 1 & 1 & 0 & 1 & 1 & 0 & 1 & 1 & 0 & 1 & 1 & 0 & 4 & 7 & $-3^{*}$ \\
\hline Halt & 9 & 3 & $6^{*}$ & 6 & 3 & 3* & 6 & 4 & 2 & 6 & 3 & $3^{*}$ & 8 & 6 & 2 \\
\hline Heyne & 11 & 7 & 4* & 11 & 10 & 1 & 9 & 9 & 0 & 7 & 9 & -2 & 10 & 10 & 0 \\
\hline Jagger & 6 & 2 & $4^{*}$ & 8 & 6 & 2 & 3 & 2 & 1 & 2 & 2 & 0 & 1 & 1 & 0 \\
\hline Norstar & 12 & 12 & 0 & 12 & 12 & 0 & 12 & 12 & 0 & 12 & 12 & 0 & 12 & 12 & 0 \\
\hline Prowers 99 & 8 & 9 & -1 & 10 & 11 & -1 & 11 & 11 & 0 & 11 & 11 & 0 & 11 & 9 & 2 \\
\hline Siouxland & 5 & 10 & $-5^{*}$ & 5 & 9 & $-4^{*}$ & 10 & 10 & 0 & 10 & 10 & 0 & 6 & 11 & $-5^{*}$ \\
\hline TAM 107 & 4 & 4 & 0 & 2 & 2 & 0 & 2 & 3 & -1 & 3 & 4 & -1 & 7 & 5 & 2 \\
\hline Yumar & 2 & 6 & $-4 *$ & 3 & 5 & -2 & 4 & 5 & -1 & 4 & 7 & $-3^{*}$ & 9 & 8 & 1 \\
\hline
\end{tabular}

* Differences $>2$ rankings.

$\dagger$ Cultivars Halt and Yumar not grown at Akron in 1999-2000.

was not observed (Fig. 7; McMaster et al. 2003). Based on DOY, only for the first planting date (PD1) in 1998 and PD2 in 1999 was jointing reached significantly earlier in the $+3 \mathrm{C}$ treatment $(P=0 \cdot 001)$. Interestingly, maturity showed more of the expected response in that the $+3 \mathrm{C}$ treatment was slightly earlier than the $+0 \mathrm{C}$ treatment (significantly so for the first two planting dates), despite the shoot apex being located above the soil surface from jointing to maturity (Fig. 7). Although the data are not shown, patterns similar to maturity were observed for flag leaf complete, heading and anthesis growth stages.

Seedlings emerged a few days earlier in the $+3 \mathrm{C}$ treatment for all planting dates (McMaster et al. 2003), and may account for differences in thermal time (air GDD) accumulated (Fig. 7) for the treatments to reach jointing. However, there was no significant difference between temperature treatments for any planting date within either year in reaching jointing $(P=0.74$ for 1998 and $P=0.58$ for 1999$)$, indicating that heating the soil did not increase the rate of phenological development as expected. There was a highly significant planting date effect caused by PD1 in both years (low GDD to jointing in 1998, and high GDD to jointing in 1999). The general expectation that planting date would be inversely related to air thermal time to reach a growth stage (Nuttonson 1955), was found for three of the four growth stagesyears (not for jointing in 1998; Fig. 7). Also, the thermal time to jointing for this spring wheat more closely matched the observed time from 1 January to jointing for winter wheat at the ARDEC location than Akron in Expt I, although this experimental site was only about $15 \mathrm{~km}$ from the ARDEC site.

Considering thermal time accumulation from emergence to jointing based on soil temperature, the $+3 \mathrm{C}$ treatment had significantly greater GDD than the $+0 \mathrm{C}$ treatment for both jointing and maturity (Fig. 7; $P<0.001$ ). This would be expected since heating the soil did not increase phenological development but would have increased the accumulated GDD. A highly significant planting date effect was also observed for both jointing and maturity in both years, and this matched the results found for GDD calculated using air temperature where thermal time from emergence to any specific stage decreased with 

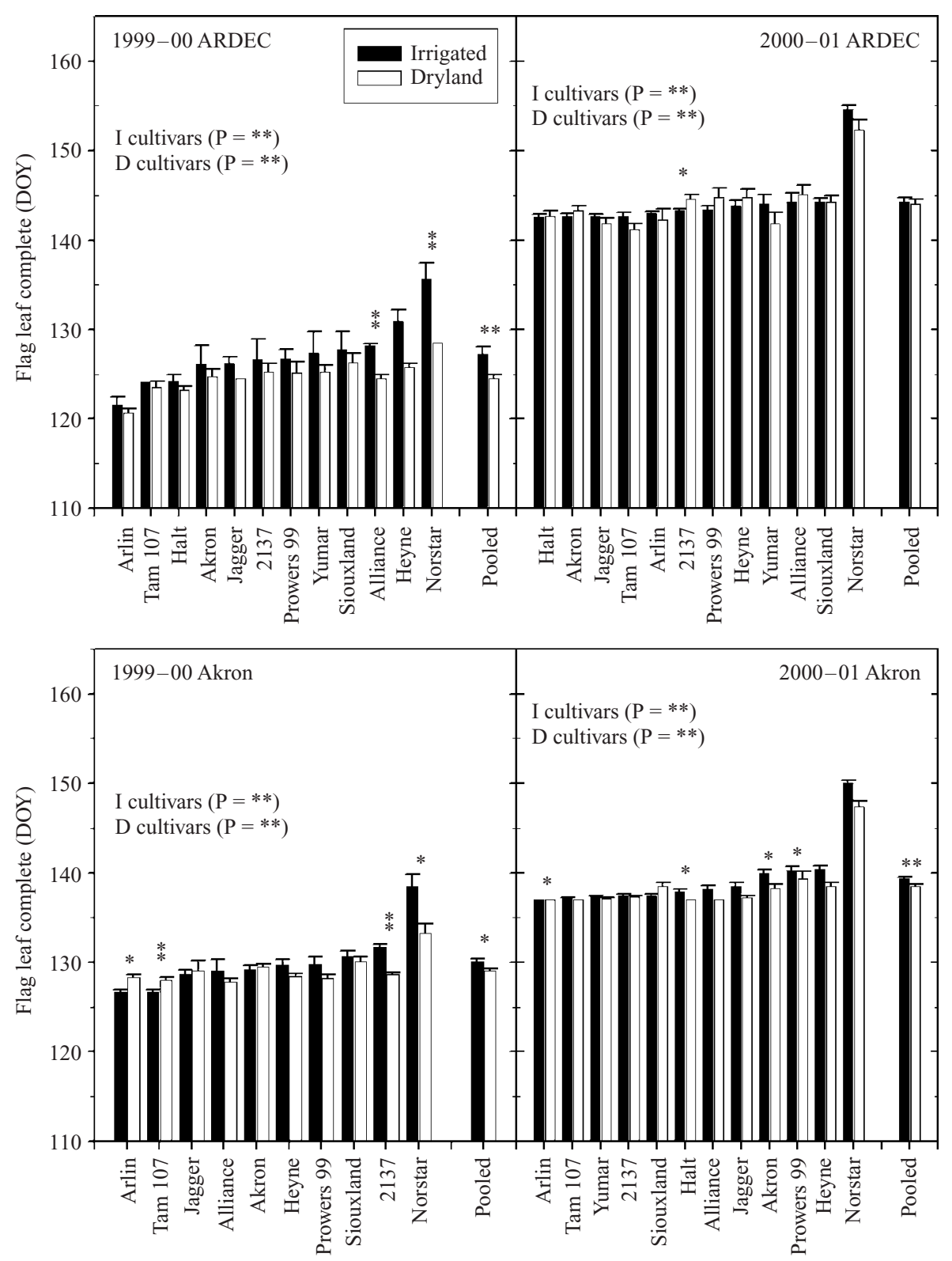

Fig. 2. Day of year flag leaf complete/beginning of booting was reached for the winter wheat water stress experiment at ARDEC and Akron locations (Expt I). Statistical results for comparing cultivar differences within a treatment (I=irrigated, $\mathrm{D}=$ dryland) are presented below the site-year label. Comparison of irrigated with dryland results for each cultivar (or the pooled means) are noted above the bars. A single asterisk denotes significant at 0.05 level, and double asterisk significant at $0 \cdot 01$ level.

later planting date. Thermal time based on soil temperature to reach a growth stage was greater than thermal time based on air temperature, implying that current thermal estimates, based on air temperature, would need to be adjusted upward if soil temperature were used.

\section{DISCUSSION}

Both Expts I and II showed that if there was a phenological response to water stress, it was to speed development. Clearly the growth stage of maturity was most influenced by water stress, with anthesis and 

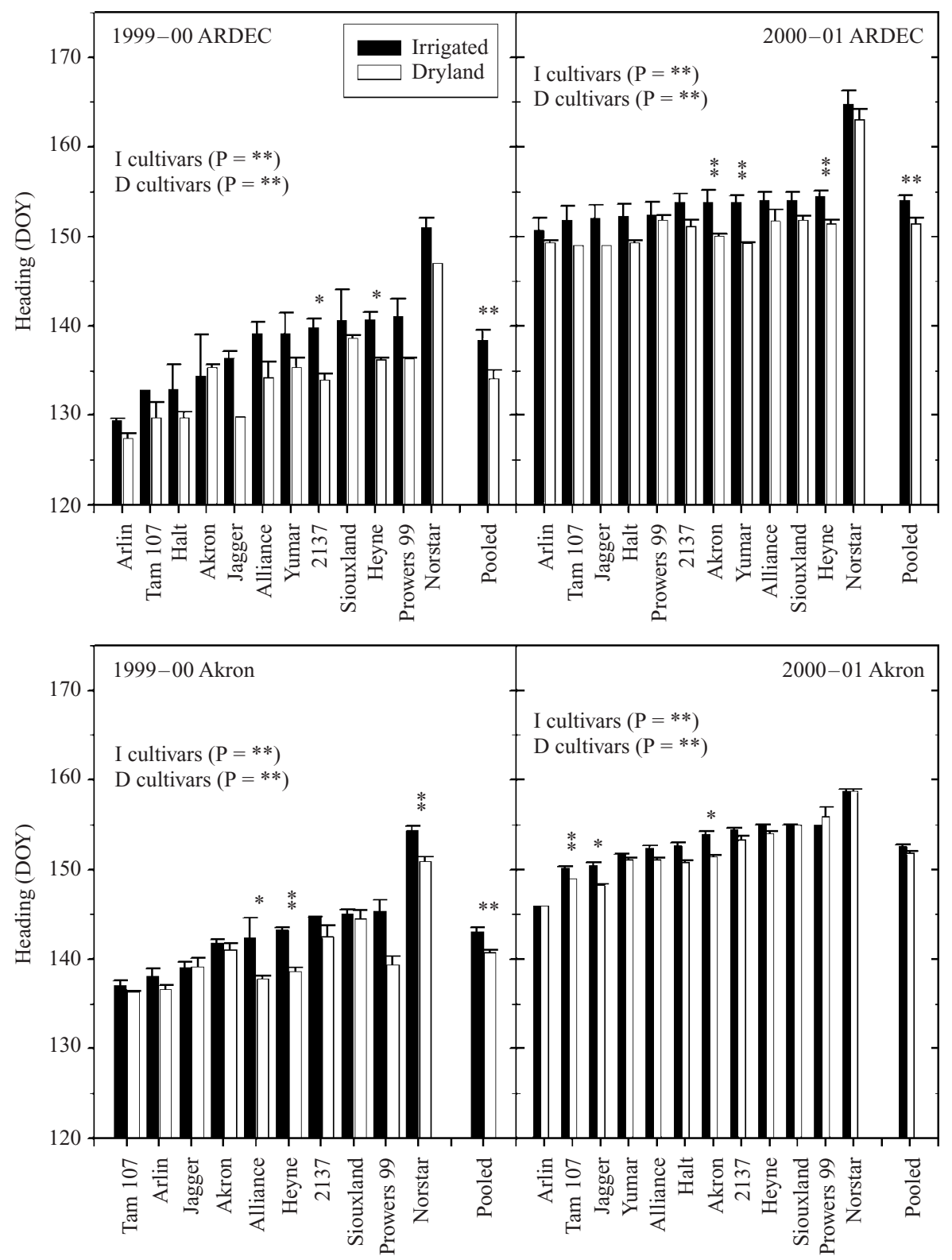

Fig. 3. Day of year heading was reached for the winter wheat water stress experiment at ARDEC and Akron locations (Expt I). Statistical results for comparing cultivar differences within a treatment $(\mathrm{I}=$ irrigated, $\mathrm{D}=$ dryland $)$ are presented below the site-year label. Comparison of irrigated to dryland results for each cultivar (or the pooled means) are noted above the bars. A single asterisk denotes significant at 0.05 level, and double asterisk significant at 0.01 level.

heading also showing a significant, but less dramatic, response. The earlier growth stages of jointing and flag leaf complete (i.e. beginning of booting) generally showed little response to water stress. Similar responses have been noted before in small-grain cereals (Nuttonson 1955; Bauer et al. 1984; Baker et al. 1986;
McMaster 1997). For example, Frank \& Bauer (1984) showed much smaller differences between different soil water levels based on irrigation level for earlier growth stages such as double ridge and terminal spikelet than anthesis and maturity for several spring wheat cultivars. However, Singh et al. (1984) found a 

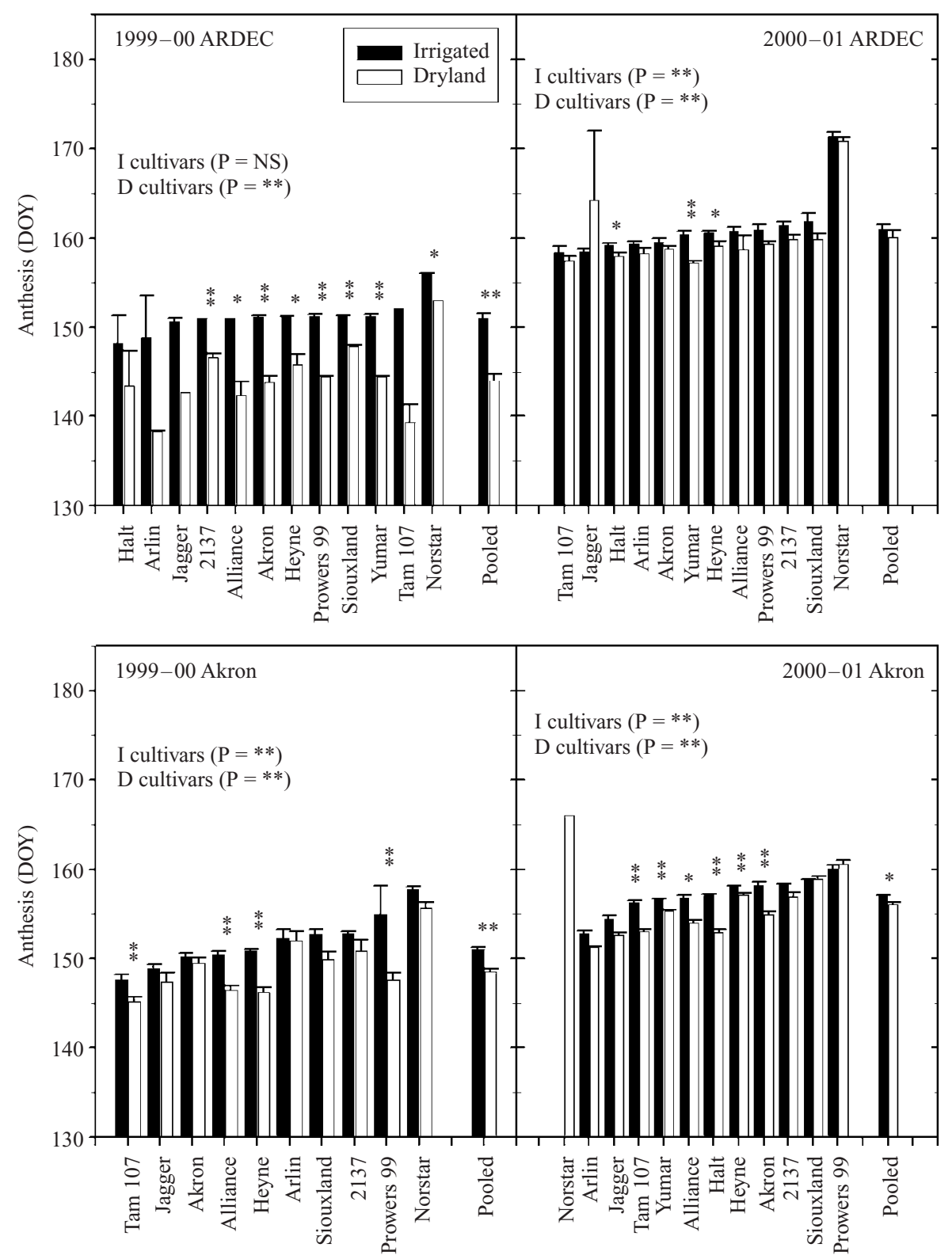

Fig. 4. Day of year anthesis started for the winter wheat water stress experiment at ARDEC and Akron locations (Expt I). Statistical results for comparing cultivar differences within a treatment ( $\mathrm{I}=$ irrigated, $\mathrm{D}=$ dryland) are presented below the site-year label. Comparison of irrigated to dryland results for each cultivar (or the pooled means) are noted above the bars. A single asterisk denotes significant at 0.05 level, and double asterisk significant at 0.01 level.

significant response of three cultivars to soil water levels for the growth stages of tillering (preceding jointing) heading and maturity, although the actual thermal time differences were less than $5 \%$ and similar for all growth stages.

To simulate a generic winter wheat response to water stress in simple phenology submodels, thermal time can be determined by pooling all cultivars for all site-years (Table 6). Based on the data reported in the present paper and the reported literature, little would be gained by assuming a phenological response for the jointing and flag leaf complete growth stages. For heading and anthesis, the present authors suggest reducing the thermal time determined in optimal 

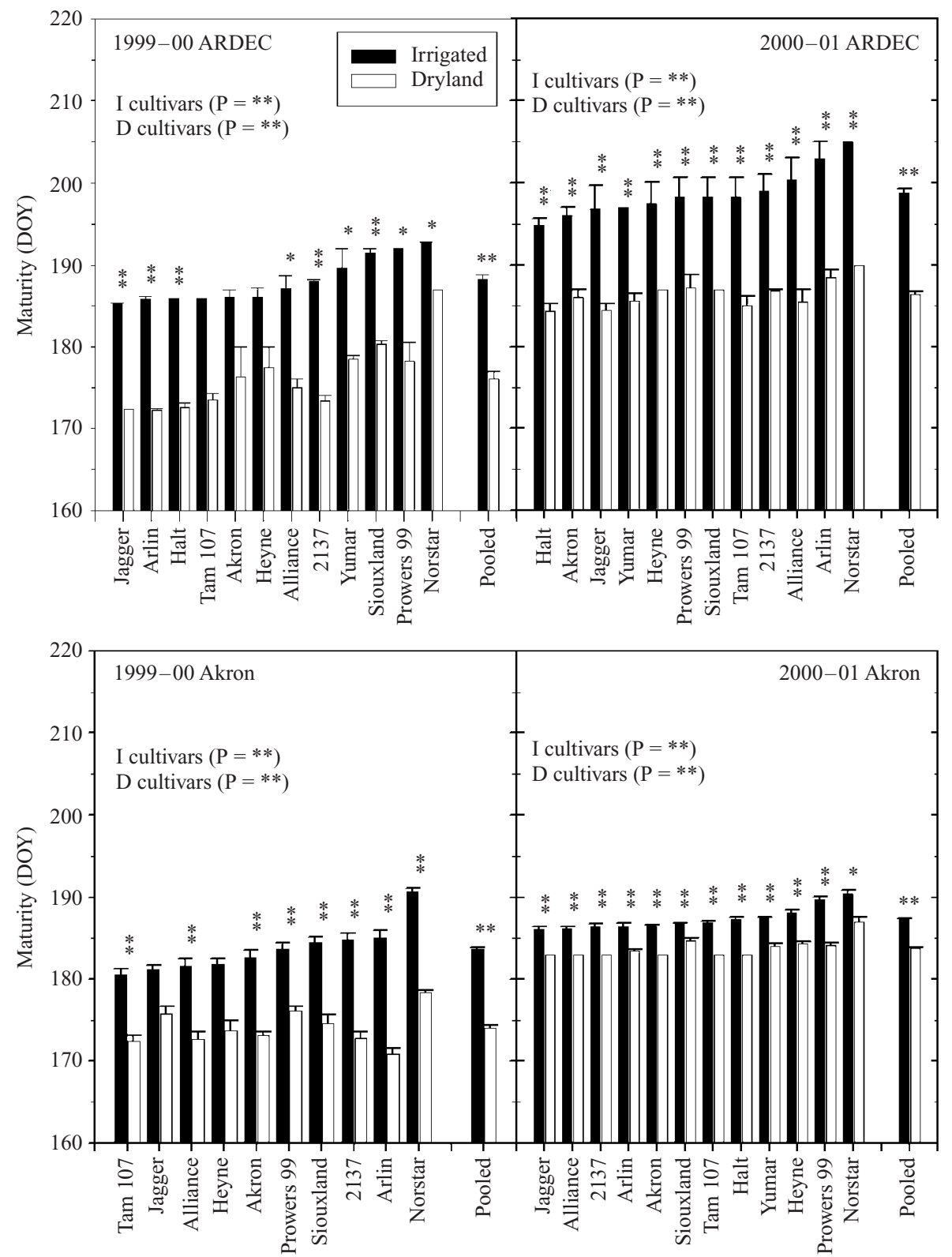

Fig. 5. Day of year physiological maturity was reached for the winter wheat water stress experiment at ARDEC and Akron locations (Expt I). Statistical results for comparing cultivar differences within a treatment $(I=$ irrigated, $D=d r y l a n d)$ are presented below the site-year label. Comparison of irrigated to dryland results for each cultivar (or the pooled means) are noted above the bars. A single asterisk denotes significant at 0.05 level, and double asterisk significant at 0.01 level.

conditions by $12 \%$ for conditions of significant water stress. The primary response is during the grain-filling interval, where a $22 \%$ decrease in thermal time determined in optimal conditions for severe water stress is suggested.

The minimal response observed for earlier growth stages such as jointing and flag leaf complete could largely be due to small differences in available water in the irrigation and dryland treatments and to little cumulative stress. Later growth stages occur at much higher temperatures when evaporative demand is high, which would cause greater water stress and higher plant temperatures. Indeed, the water stress response would likely have been greater if irrigation 

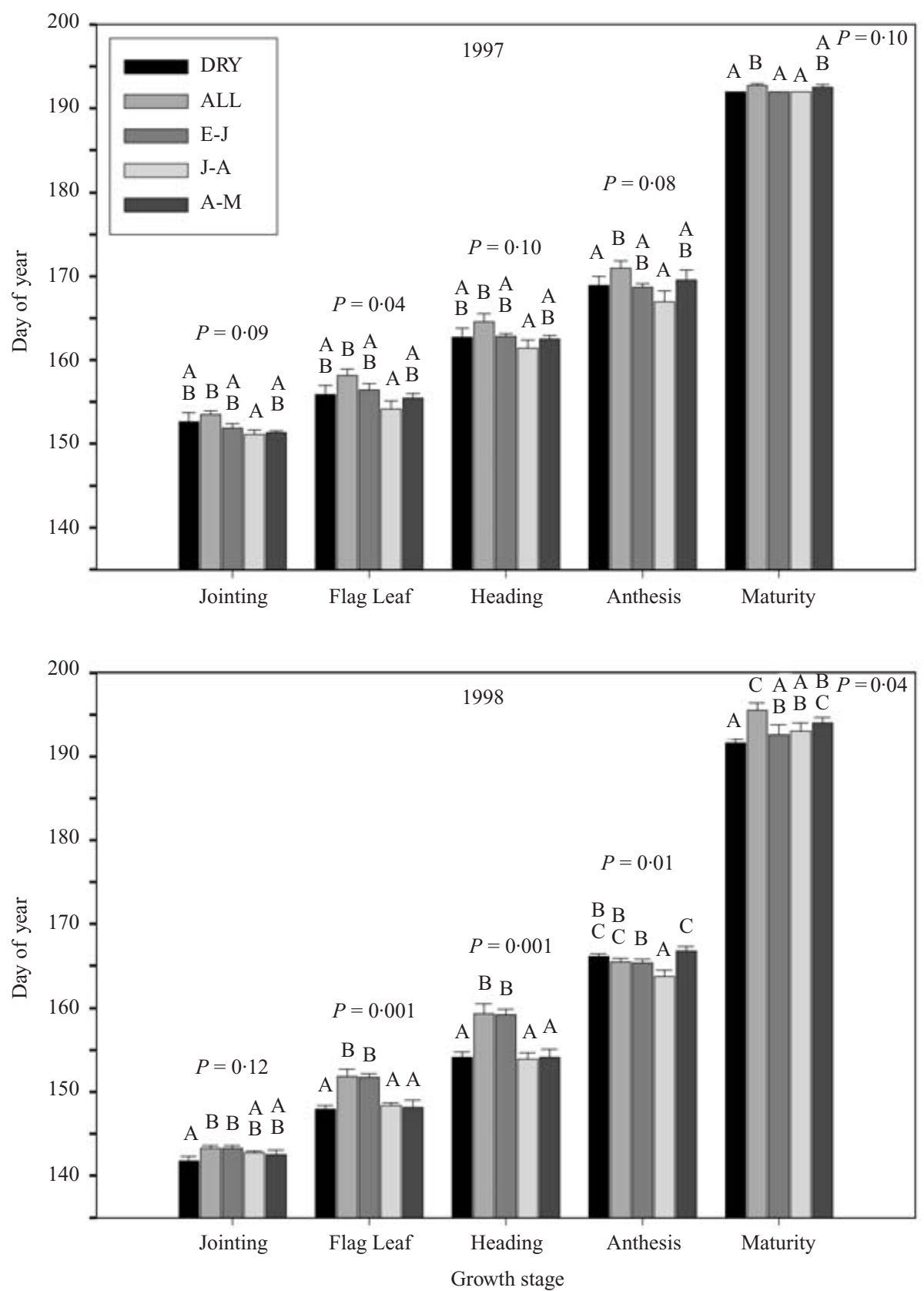

Fig. 6. Day of year that growth stages were reached for spring barley as a function of irrigation treatment, where pre-plant tillage results were combined because tillage had no effect on phenology (Expt II). DRY denotes the control dryland treatment, ALL is irrigated from emergence (E) to physiological maturity (M), E-J is irrigated from E to jointing (J), J-A is irrigated from $\mathrm{J}$ to anthesis (A), and A-M is irrigated from A to $\mathrm{M}$. The probability of accepting the null hypothesis (i.e. no differences among the treatments) is given above each growth stage, with LSD $(0 \cdot 05$ or $0 \cdot 10$ depending on probability) results noted using letters. 

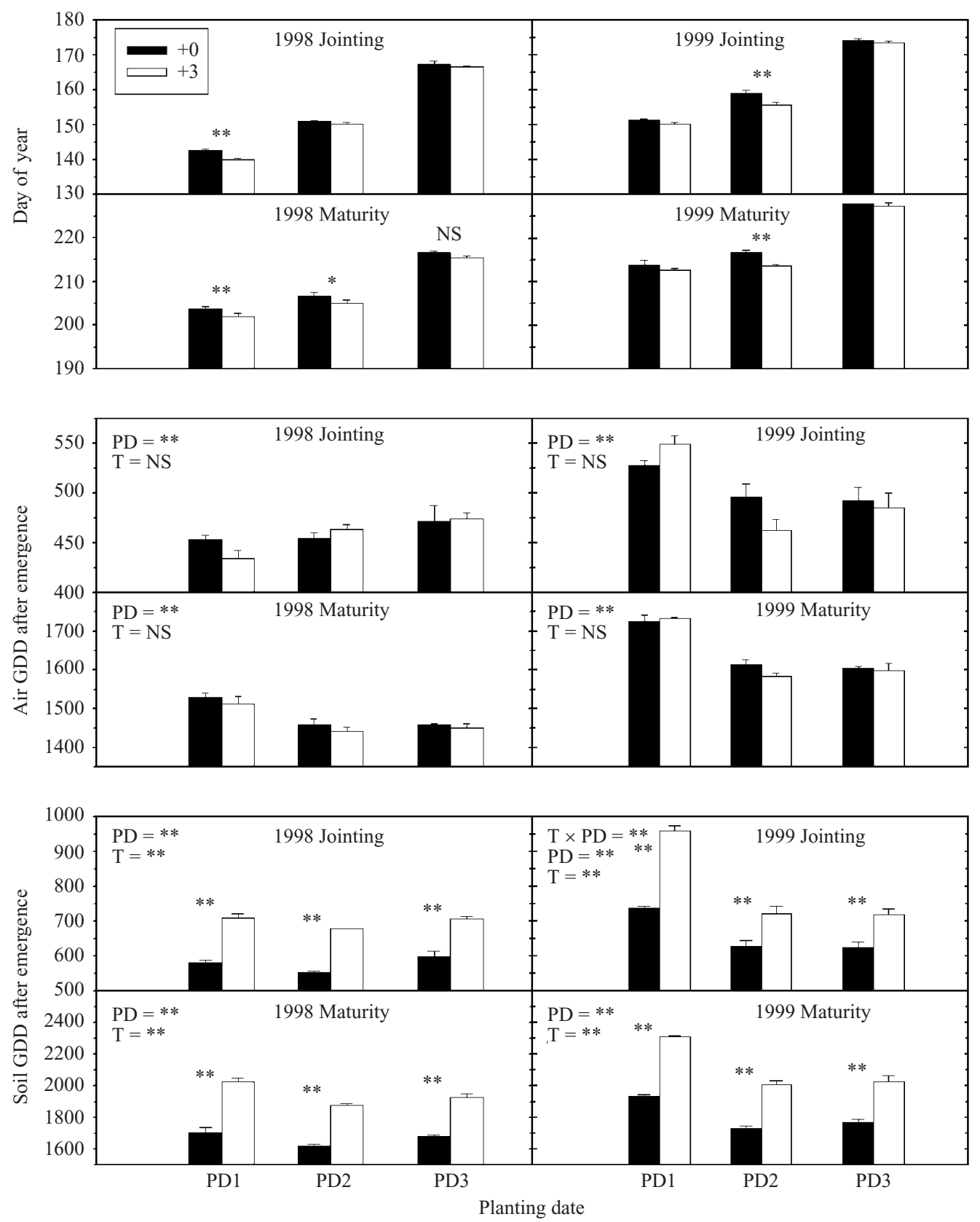

Fig. 7. Heat treatment and planting date effects on jointing and physiological maturity dates or thermal time (air or soil growing degree-days after seedling emergence) for the spring wheat temperature experiment (Expt III). Statistical results within each individual graph for planting date $(=\mathrm{PD})$ and temperature $(\mathrm{T})$ treatments are listed in the upper left corner of the thermal time graphs (not done for day of year because planting date differences are meaningless). Differences between temperature treatments for a planting date are noted with either a single asterisk if significant at the $0 \cdot 05$ level or double asterisk if significant at the $0 \cdot 01$ level. 
Table 6. Thermal time (in growing degree-days, GDD) between growth stages combining all winter wheat cultivars for both years at both sites (ARDEC and Akron, Expt I)

\begin{tabular}{lccrr}
\hline \hline Growth stage interval & Irrigated & Dryland & Difference & $(\%) \S$ \\
\hline 1 Jan-Jointing $\dagger$ & 607 & 599 & 8 & $98 \cdot 7$ \\
1 Jan-Jointing & 484 & 486 & -2 & $100 \cdot 4$ \\
Jointing-Flag leaf complete & 158 & 152 & 6 & $96 \cdot 2$ \\
Flag leaf complete-Heading & 164 & 143 & 21 & $87 \cdot 2$ \\
Heading-Anthesis & 133 & 117 & 16 & $88 \cdot 0$ \\
Anthesis-Maturity & 710 & 557 & 153 & $78 \cdot 5$ \\
\hline \hline
\end{tabular}

$\dagger$ For both ARDEC and Akron sites.

$\$$ For ARDEC site only.

$\S[1-($ Irrigated GDD - Dryland GDD)/Irrigated GDD $] \times 100$.

treatments were frequent enough to alleviate all water stress, but this was not realistically possible in the present experiments. The jointing to flag leaf complete interval is further confounded by the stage of leaf development when jointing is reached. Rickman \& Klepper (1991) note great variability in the timing of this stage, with 1-2 leaves appearing over the interval. The leaf appearing when jointing is first reached, as well as any subsequent leaves, must complete their growth before the flag leaf completes growth. This variation can account for nearly one phyllochron of difference in plants within the same canopy reaching FLC. One phyllochron is typically about 108 GDD (Frank \& Bauer 1995). This variability in predicting FLC likely carries over into predictions of heading.

As mentioned briefly in the results, for unknown reasons the thermal time estimates for jointing at Akron were much greater than for ARDEC and other reported literature (McMaster \& Smika 1988; McMaster et al. 1992 b; McMaster 1997). The present authors believe thermal time estimates from ARDEC are probably more universally reliable for modelling purposes. The jointing growth stage has been the most difficult of the five growth stages that were observed to simulate accurately (McMaster et al. 1992b; McMaster \& Wilhelm 1998). It is likely that the simple calculation of thermal time for jointing is less robust than for other growth stages because of the influence of photoperiod and vernalization (Davidson et al. 1985; Masle et al. 1989; McMaster 1997) in inducing the onset of reproductive development in the shoot apex. Clearly more work is needed on understanding the controls on jointing if predictions are to be improved. It is, however, encouraging that once jointing is reached (although quite variable among locations) the thermal intervals for successive growth stages and the response to water, are quite consistent.

Using Table 6, two options for setting thermal time parameters for growth stage intervals are possible. If the approach is to set static thermal time regardless of water stress conditions (e.g. EPIC, ALMANAC,
CERES-wheat, ModWHT and SHOOTGRO 2.0 models), then thermal estimates must be used based on the type of conditions typically expected. For instance, in irrigated situations or locations with high precipitation rates the use of irrigated thermal time estimates would be best. For dryland situations in regions of low precipitation the dryland thermal estimates might be best. If moderate water stress conditions are being simulated, then averaging the irrigated and thermal estimates is suggested. The other approach is to reduce thermal time estimates for growth stage intervals based on degree of water stress (e.g. SHOOTGRO 4.0; Zalud et al. 2003). In this approach, the upper (irrigated), lower (dryland), and 'mid-point' (combined) thermal time estimates can be used to generate the first approximation of a linear response to water stress. While water stress response is likely to be non-linear, data do not exist to quantify this relationship in a more appropriate manner. Data in Table 6 gives the extreme responses to water stress ('optimal' is represented by irrigated values and 'severe stress' by dryland values). When using values from the literature, it is important to discern the relative degree of water stress.

While the phenological responses to water stress for a generic cultivar are relatively straightforward, simulating cultivar responses is not. Historically, thermal time estimates have been adjusted based on maturity class of the cultivar in simulation models. Some information is available on maturity class, which has traditionally been defined as relative time to heading, that might be used to modify Table 6 values for specific cultivars (Haley 2003; Watson 2003). There are several possible problems with using this information. First, the heading class information does not always agree or match our observed data. Second, maturity class (based on heading date) may or may not be related to either time for jointing or maturity. Third, depending on cultivar and growth stage, varying degrees of genotype by environment $(\mathrm{G} \times \mathrm{E})$ interaction are likely. 
Sources of relative heading dates (maturity class) for many cultivars can be obtained with varying amounts of effort, and while normally qualitative in nature, they usually agree. Occasionally, a cultivar may be ranked differently such as Heyne, which is ranked 'early' by Haley (2003) and 'medium' by Watson (2003), but because it is a qualitative ranking, it is difficult to know the absolute difference in thermal time. In addition, most maturity class assignments are established on a relative, rather than absolute, basis. That is, maturity rating is accomplished by comparing new genotypes or cultivars time of heading (or other developmental stage) to a standard cultivar grown in the region (often grown in the same experiment). If the objective of a modelling exercise is to investigate the performance of new cultivar or an established cultivar grown in a new production region or environment, these relative maturity data are not available. Further, by basing maturity rating on comparisons between standard cultivars and new cultivars, the data collected are in many ways tempered for $\mathrm{G} \times \mathrm{E}$ interactions. This limits the usefulness of readily available maturity data as an input to a model constructed to describe and account for differences in the $\mathrm{G} \times \mathrm{E}$ interaction among cultivars.

Few data are readily available for comparing relative rankings of other growth stages, such as jointing and maturity, in relation to heading. Watson (2003) gives information for jointing for four of our cultivars. Watson ranks 2137 as 'medium-late' (which agrees with the data from the present experiment), Heyne and Jagger as 'early' (does not agree with the present data) and TAM 107 as 'medium-early' (does not agree with the present data).

For several cultivars, Halt, Heyne, Norstar and Siouxland, the present data show that maturity ratings based on $\mathrm{H}$ are related to the interval from $\mathbf{J}$ to M. In fact, these cultivars have very consistent relative rankings for $\mathrm{J}, \mathrm{H}$ and $\mathrm{M}$ (Table 7 using combined irrigation and dryland data). However, other cultivars did not rank consistently for the various stages and showed different relative rankings for $\mathbf{J}$ and $\mathrm{H}$ (e.g. Akron and Prowers 99) and $\mathrm{H}$ and M (e.g. 2137, TAM 107 and Yumar). Alliance and Jagger showed a difference for both $\mathbf{J}$ and $\mathrm{H}$ and $\mathrm{H}$ and $\mathrm{M}$ relative rankings. Caution on the relative rankings for jointing is needed, as the difference in rankings in terms of days or thermal time is normally not significant, so few meaningful differences in jointing were observed for most of our cultivars.

Given the present results, the available literature for heading class seems reasonably sufficient for considering the direction of thermal adjustments for specific cultivar responses from the generic winter wheat cultivar, but it is difficult to quantify the adjustment. However, the relationship from jointing to heading and heading to maturity is not consistent and the literature is insufficient for giving guidance on 
adjusting thermal estimates. Again, for jointing this probably is not a problem in simple phenology submodels, but for maturity it will be a problem.

The most important issue of simulating cultivar phenological responses to water stress is determining whether responses are consistent. If consistent, then it is sufficient merely to adjust the thermal time based on relative ranking for the growth stage from the generic mean, or 'medium' cultivar. For jointing and flag leaf complete, the $\mathrm{G} \times \mathrm{E}$ interaction was not a problem primarily because water stress effects rarely were observed for a specific cultivar. The inconsistency in cultivar response to water stress among cultivars for later growth stages, particularly $\mathrm{M}$, could reflect either the inherent variability of field data or be indicative of the expected $\mathrm{G} \times \mathrm{E}$ interaction. We do not know how to separate these possibilities, but either one makes simulating specific cultivars difficult. Unless a 'consistent' cultivar is being simulated, merely adjusting the thermal time for a growth stage interval for optimal conditions as is typically done, will result in error depending on how the specific cultivar responds to water stress. Fortunately, for most of the cultivars studied in the present paper, this error is within a few days (or 20 GDD) until the anthesis to maturity interval. This was well within the error of the simple, but robust, thermal time approach.

Occasionally cultivar responses showed significant $\mathrm{G} \times \mathrm{E}$ interaction for the duration of the grain filling period. This has implications for simulating grain yield. Grain yield is a function of the rate and duration of kernel growth, with duration generally being more important in determining final yield than rate (McMaster et al. 1992a,b; McMaster 1997). Duration shows a strong response to temperature (nonlinear) and water stress (also probably non-linear). Since temperature and water stress interact in complex ways for determining the duration, accurately simulating specific cultivar yield responses without understanding which cultivars deviate from the 'norm', and why, will be difficult at best.

Previous reasoning and work (Hay \& Wilson 1982; Jamieson et al. 1995; Vinocur \& Ritchie 2001) suggested that thermal estimates could be improved, and therefore better explain some results, if soil temperature near the crown was used to reflect shoot apex temperature rather than air temperature above the canopy. Unexpectedly, the results from heating the soil near the crown did not show the predicted response of faster rate of development. The same results were found for phenology in the Central Great Plains (McMaster \& Smika 1988) and phyllochron (McMaster et al. 2003). Therefore, we cannot support the added expense and effort to either measure or predict soil temperature, rather than using the readily available and measured air temperature above the canopy, as a means of consistently improving our phenology submodels. Certainly the improvement will not be universal, and at this time it is difficult to determine when it would be advantageous to do so.

\section{CONCLUSIONS}

Thermal estimates were provided for simulating winter wheat phenological responses to water stress, with the main response noted for the grain filling period (anthesis to maturity). The jointing growth stage showed the least response to water stress, but also the most variation in thermal estimates. Difficulty in accurately predicting jointing will tend to increase the error in predicting successive growth stages if using the observed approach that thermal estimates for successive growth stages remain relatively constant across site-years. The winter wheat cultivars tested showed the same general response across siteyears, but inconsistencies were found suggesting a complicated $\mathrm{G} \times \mathrm{E}$ interaction. The high variability for grain-filling duration has significant implications for accurately simulating grain yield, especially specific cultivars. Better measurement of thermal time by measuring soil temperature near the crown will not significantly improve our predictions of phenology over using readily available air temperature above the canopy.

We thank P. Byrne, S. Haley, D. Nielsen, B. Riebau and D. Palic for various contributions to this work. This study was partly funded by the Colorado Agricultural Experiment Station. We appreciate the encouragement of Prof R. E. L. Naylor to submit this manuscript.

\section{REFERENCES}

Baker, J. T., Pinter, P. J., Reginato, R. J. \& Kanemasu, E. T. (1986). Effects of temperature on leaf appearance in spring and winter wheat cultivars. Agronomy Journal 78, 605-613.

Bauer, A., Frank, A. B. \& Black, A. L. (1984). Estimation of spring wheat leaf growth rates and anthesis from air temperature. Agronomy Journal 76, 829-835.

CAo, W. \& Moss, D. N. (1989). Temperature effect on leaf emergence and phyllochron in wheat and barley. Crop Science 29, 1018-1021.
Davidson, J. L., Christian, K. R., Jones, D. B. \& Bremner, P. M. (1985). Responses of wheat to vernalization and photoperiod. Australian Journal of Agricultural Research 36, 347-359.

Frank, A. B. \& Bauer, A. (1984). Cultivar, nitrogen, and soil water effects on apex development in spring wheat. Agronomy Journal 76, 656-660.

Frank, A. B. \& Bauer, A. (1995). Phyllochron differences in wheat, barley, and forage grasses. Crop Science $\mathbf{3 5}$, 19-23. 
Haley, S. (2003). Colorado wheat variety performance database [Online]. Available http://wheat.colostate.edu/ vpt.html (verified 18 March 2003).

Haun, J. R. (1973). Visual quantification of wheat development. Agronomy Journal 65, 116-119.

HaY, R. K. M. \& Wilson, G. T. (1982). Leaf appearance and extension in field-grown winter wheat plants: the importance of soil temperature during vegetative growth. Journal of Agricultural Science, Cambridge 99, 403-410.

Jamieson, P. D., Brooking, I. R., Porter, J. R. \& Wilson, D. R. (1995). Prediction of leaf appearance in wheat: a question of temperature. Field Crops Research 41, 35-44.

Jamieson, P. D., Semenov, M. A., Brooking, I. R. \& Francis, G. S. (1998). Sirius: a mechanistic model of wheat response to environmental variation. European Journal of Agronomy 8, 161-179.

Large, E. C. (1954). Growth stages in cereals. Plant Pathology 3, 128-129.

Longnecker, N., Kirby, E. J. M. \& Robson, A. (1993). Leaf emergence, tiller growth, and apical development of nitrogen-deficient spring wheat. Crop Science 33, 154-160.

Masle, J., Doussinault, G., Farquhar, G. D. \& Sun, B. (1989). Foliar stage in wheat correlates better to photothermal time than to thermal time. Plant Cell and Environment 12, 235-247.

MaAs, E. V. \& Grieve, C. M. (1990). Spike and leaf development in salt-stressed wheat. Crop Science 30, 1309-1313.

McMaster, G. S. (1993) Another wheat (Triticum spp.) model? Progress and applications of crop modeling. Rivista di Agronomia 27, 264-272.

McMaster, G. S. (1997). Phenology, development, and growth of the wheat (Triticum aestivum L.) shoot apex: a review. Advances in Agronomy 59, 63-118.

McMaster, G. S. \& Smika, D. E. (1988). Estimation and evaluation of winter wheat phenology in the central Great Plains. Agricultural and Forest Meteorology 43, 1-18.

McMaster, G. S. \& Wilhelm, W. W. (1997). Growing degree-days: one equation, two interpretations. Agricultural and Forest Meteorology 87, 291-300.

McMaster, G. S. \& Wilhelm, W. W. (1998). Is soil temperature better than air temperature for predicting winter wheat phenology? Agronomy Journal 90, 602-607.

McMaster, G. S., Klepper, B., Rickman, R. W., Wilhelm, W. W. \& Willis, W. O. (1991). Simulation of shoot vegetative development and growth of unstressed winter wheat. Ecological Modelling 53, 189-204.

McMaster, G. S., Morgan, J. A. \& Wilhelm, W. W. (1992a). Simulating winter wheat spike development and growth. Agricultural and Forest Meteorology 60, 193-220.

McMaster, G. S., Wilhelm, W. W. \& Morgan, J. A. (1992b). Simulating winter wheat shoot apex phenology. Journal of Agricultural Science, Cambridge 119, 1-12.

McMaster, G. S., Wilhelm, W. W. \& Bartling, P. N. S. (1994). Irrigation and culm contribution to yield and yield components of winter wheat. Agronomy Journal 86, 1123-1127.

McMaster, G. S., Lecain, D. R., Morgan, J. A., Aiguo, L. \& Hendrix, D. L. (1999). Elevated $\mathrm{CO}_{2}$ increases CER, leaf and tiller development, and shoot and root growth. Journal of Agronomy and Crop Science 183, 119-128.
McMaster, G. S., Palic, D. B. \& Dunn, G. H. (2002). Soil management alters seedling emergence and subsequent autumn growth and yield in dryland winter wheat-fallow systems in the Central Great Plains on a clay loam soil. Soil and Tillage Research 65, 193-206.

McMaster, G. S., Wilhelm, W. W., Palic, D. B., Porter, J. R. \& JAmieson, P. D. (2003). Spring wheat leaf appearance and temperature: extending the paradigm. Annals of Botany 91, 697-705.

Nuttonson, M. Y. (1955). Wheat-Climate Relationships. Washington, DC: American Institute of Crop Ecology.

Rickman, R. W. \& Klepper, E. L. (1991). Tillering in wheat. In Predicting Crop Phenology (Ed. T. Hodges), pp. 73-84. Boca Raton, FL: CRC Press.

Rickman, R. W., Waldman, S. E. \& Klepper, B. (1996). MODWht3: a development-driven wheat growth simulation. Agronomy Journal 88, 176-185.

SAS Institute (1991). SAS Language and Procedures, Ver. 6.0. Cary, NC: SAS Institute.

Singh, N. T., Aggarwal, G. C. \& Brar, G. S. (1984). Effect of soil-moisture stress on heat-unit requirement of wheat at maturity. Indian Journal of Agricultural Science 54, $442-444$.

Streck, N. A., Weiss, A., Xue, Q. \& Baenzinger, P. S. (2003). Improving predictions of developmental stages in winter wheat: a modified Wang and Engel model. Agricultural and Forest Meteorology 115, 139-150.

Vinocur, M. G. \& Ritchie, J. T. (2001). Maize leaf development biases caused by air-apex temperature differences. Agronomy Journal 93, 767-772.

Watson, S. (2003). Wheat varieties for Kansas and the Great Plains 2003. Topeka, KS: Lone Tree Publishing Company.

Weir, A. H., Bragg, P. L., Porter, J. R. \& Rayner, J. H. (1984). A winter wheat crop simulation model without water or nutrient limitations. Journal of Agricultural Science, Cambridge 102, 371-382.

Wilhelm, W. W. \& McMaster, G. S. (1995). The importance of the phyllochron in studying the development of grasses. Crop Science 35, 1-3.

Wilhelm, W. W., McMaster, G. S., Rickman, R. W. \& Klepper, B. (1993). Above ground vegetative development and growth of winter wheat as influenced by nitrogen and water availability. Ecological Modelling 68, 183-203.

Williams, J. R., Jones, C. A., Kiniry, J. R. \& Spanel, D. A. (1989). The EPIC crop growth model. Transactions of the ASAE 32, 497-511.

WILlis, W. O. (1985). ARS Wheat Yield Project. United States Department of Agriculture, Agricultural Research Service ARS-38.

YAN, W. \& HunT, L. A. (1999). An equation for modelling the temperature response of plants using only the cardinal temperatures. Annals of Botany 84, 607-614.

Zadoks, J. C., Chang, T. T. \& KonzaK, C. F. (1974). A decimal code for the growth stages of cereals. Weed Research 14, 415-421.

Zalud, Z., McMaster, G. S. \& Wilhelm, W. W. (2003). Parameterizing SHOOTGRO 4.0 to simulate winter wheat phenology and yield in the Czech Republic. European Journal of Agronomy 19, 495-507. 